\title{
The relation between QTc interval prolongation and diabetic complications. The EURODIAB IDDM Complication Study Group
}

\author{
M. Veglio ${ }^{1}$, M. Borra ${ }^{2}$, L. K. Stevens ${ }^{3}$, J.H. Fuller ${ }^{3}$, P. C. Perin ${ }^{2}$ \\ and the EURODIAB IDDM Complications Study Group* \\ ${ }^{1}$ Ospedale Mauriziano, Torino, Italy \\ ${ }^{2}$ Department of Internal Medicine, Ospedale San Giovanni Battista di Torino, Torino, Italy \\ ${ }^{3}$ EURODIAB, Department of Epidemiology and Public Health, University College of London, London, UK
}

\begin{abstract}
Summary The prevalence of QT interval prolongation is higher in people with diabetes and its complications. Sudden death has been reported as a common cause of death in insulin-dependent diabetic patients affected by autonomic neuropathy. It has been postulated that QT prolongation predisposes to cardiac arrhythmias and sudden death. In this analysis the prevalence of QT interval prolongation and its relation with diabetic complications were evaluated in the EURODIAB IDDM Complications Study (3250 insulin-dependent diabetic patients attending 31 centres in 16 European countries). Five consecutive RR and QT intervals were measured with a ruler on the V5 lead of the resting ECG tracing and the QT interval corrected for the previous cardiac cycle length was calculated according to the Bazett's formula. The prevalence of an abnormally prolonged corrected QT was $16 \%$ in the whole population, $11 \%$ in males and $21 \%$ in females $(p<0.001)$. The mean corrected QT was $0.412 \mathrm{~s}$ in males and $0.422 \mathrm{~s}$ in females
\end{abstract}

$(p<0.001)$. Corrected QT duration was independently associated with age, $\mathrm{HbA}_{1 \mathrm{c}}$ and blood pressure. Corrected QT was also correlated with ischaemic heart disease and nephropathy but this relation appeared to be stronger in males than in females. Male patients with neuropathy or impaired heart rate variability or both showed a higher mean adjusted corrected QT compared with male patients without this complication. The relation between corrected QT prolongation and autonomic neuropathy was not observed among females. In conclusion we have shown that corrected QT in insulin-dependent diabetic female patients is longer than in male patients, even in the absence of diabetic complications known to increase the risk of corrected QT prolongation. [Diabetologia (1999) 42: 68-75]

Keywords Insulin-dependent diabetes mellitus, corrected QT interval, QT prolongation, prevalence, neuropathy, nephropathy, ischaemic heart disease.
The QT interval reflects the total duration of ventricular myocardial depolarization and repolarization: a prolonged QT interval is associated with sudden death and poor survival in apparently healthy sub-

Received: 17 April 1998 and in final revised form: 2 September 1998

Corresponding author: Dr. M. Veglio, via Mancini 15, 10131 Torino, Italy

Abbreviations: IHD, Ischaemic heart disease; AER, albumin secretion rate; QTc, corrected QT interval.

* See Acknowledgements for complete list of participating investigators, hospitals and clinics jects [1]. The relation of QT interval prolongation with diabetes complications, poor survival prognosis and sudden death has recently received considerable interest. It has been postulated that QT prolongation accounts for higher mortality in people with diabetes and its complications as the prevalence of QT interval prolongation is higher among patients with Type I (insulin-dependent) diabetes mellitus [2], ischaemic heart disease (IHD) [3-7], end stage renal disease [8] and autonomic neuropathy [2,9-12].

Data on QT interval in diabetic patients are, however, mainly derived from small, selected samples [9-15]. In particular, the prevalence of QT interval prolongation and its relation with cardiac autonomic neuropathy has been evaluated in only one cross-sec- 
tional study on a randomly selected Type I diabetic group [2]. Moreover, previous studies did not adjust for confounders such as age and $\mathrm{HbA}_{1 \mathrm{c}}$ and combined the results for both sexes, which could provide misleading results due to the known differences in QT interval duration between males and females [1, 16].

The EURODIAB IDDM Complications Study is a cross-sectional clinic-based study of complications in 3250 randomly selected Type I diabetic patients attending 31 centres in 16 European countries. The prevalence of acute metabolic and chronic complications (nephropathy, retinopathy and neuropathy) in this study has recently been reported [17]. The aims of the present analyses were to evaluate the prevalence of QT interval prolongation in the EURODIAB IDDM Complications Study and its relation to sex, age, diabetes duration, metabolic control and complications.

\section{Subjects and methods}

Details on the subjects and the procedures of the EURODIAB study have been published elsewhere [17]. In brief, 3250 patients with Type I diabetes were studied in 31 centres in 16 countries across Europe. There were 1668 males and $1582 \mathrm{fe}-$ males. Their mean (SD) age was 32.7 (10.7) years and duration of diabetes was 14.7 (9.3) years. $\mathrm{HbA}_{1 \mathrm{c}}$ was centrally assessed with an enzyme immunoassay and the mean (SD) was $6.7(1.9) \%$.

All patients completed a questionnaire on demographic variables, health related behaviours and diabetes history. Retinopathy was assessed by retinal photographs centrally graded by a single observer: each patient's level of retinopathy (absent, background or proliferative) was determined by the worse eye [18]. Nephropathy was assessed using albumin excretion rate (AER) calculated centrally from a single timed $24 \mathrm{~h}$ urine collection. Normoalbuminuria was defined as AER less than $20 \mu \mathrm{g} / \mathrm{min}$, microalbuminuria as AER between $20 \mu \mathrm{g} / \mathrm{min}$ and $200 \mu \mathrm{g} / \mathrm{min}$, and macroalbuminuria as AER above $200 \mu \mathrm{g} / \mathrm{min}$ [19].

For the assessment of sensory neuropathy, vibration perception threshold was measured using centrally calibrated biothesiometres and age-related reference values [20]. Autonomic neuropathy was assessed by measuring the change in heart rate (heart rate variability) and blood pressure (postural hypotension) on standing upright after resting supine for at least $5 \mathrm{~min}$. The cardiovascular tests were done and evaluated according to the Ewing method [21]. A single observer calculated the postural change in ECG-recorded heart rate as the ratio of the longest R-R interval between the 28th and 32nd beats following standing to the shortest interval between the 13th and 17 th beats. Blood pressure was measured once in the horizontal position and once $60 \mathrm{~s}$ after standing using a Hawksley random zero sphygmomanometer (Hawksley and Son, Lancing, UK). Diabetic autonomic neuropathy was diagnosed in the presence of postural hypotension with a fall in systolic blood pressure of $30 \mathrm{mmHg}$ or more or loss of heart rate variability or both $(\mathrm{R}-\mathrm{R}$ ratio $<1)$. Patients were asked about the presence of symptoms suggestive of neurological damage and ankle and knee reflexes were assessed. The presence of neuropathy was defined as 2 out of 4 abnormalities among vibration perception threshold, cardiovascular tests, symptoms and an$\mathrm{kle} / \mathrm{knee}$ reflexes.

The presence of IHD was determined on the basis of 1) a structured standardized questionnaire concerning the past history of angina or myocardial infarction and 2) a resting ECG which was registered at a $25 \mathrm{~mm} / \mathrm{sec}$ speed and $10 \mathrm{~mm} / \mathrm{mV}$ gain and centrally classified according to Minnesota Codes [22].

QT interval. RR and QT intervals were measured with a ruler on the resting ECG tracing which was available for 3147 patients: five consecutive beats were considered on lead V5. The QT interval was taken from the beginning of the QRS complex to the end of the downslope of the T wave (crossing of the isoelectric line) [23]. The QT interval corrected for the previous cardiac cycle length (QTc) was calculated according to the formula proposed previously [24] and known as Bazett's formula [25]: QTc $=\mathrm{QT} /(\mathrm{RR})^{1 / 2}$. Two observers unaware of the grouping of any subject measured all the intervals and the QTc for each subject was taken as the mean value of the five calculated intervals and the mean of the reading of the two observers to minimize inter-observer variability as proposed previously [12]. QTc greater than $0.44 \mathrm{~s}$ was considered abnormally prolonged, in accordance with the criteria commonly used in the literature $[1,26,27]$.

Statistical analysis. The $t$-test and chi-squared test were used to test for group differences of crude means and crude proportions respectively. Mean QTc levels were adjusted for confounding factors and group differences between means assessed using least squares regression. Also, sex differences in the associations between QTc and complications were assessed by comparing regression coefficients and by including an interaction term in the regression models. Standardised regression coefficients were calculated, for a continuous variable, as the change in QTc duration associated with a raise of 1 standard deviation of the variable and, for a categorical variable, as the amount of QTc duration associated with the variable being present compared to it being absent. Proportions of abnormal QTc (QTc > $0.44 \mathrm{~s})$ were directly standardized to the age and $\mathrm{HbA}_{1 \mathrm{c}}$ distributions of the whole sample, and group differences assessed using the extended Mantel Haenszel chi-square test. To assess sex differences of associations between abnormal QTc and complications, contingency coefficients were compared. The statistical analysis was made using the statistical package SAS.

\section{Results}

The prevalence of an abnormally prolonged QTc in the whole population was $16 \%$. The mean QTc was $0.412 \mathrm{~s}$ in males and $0.422 \mathrm{~s}$ in females $(p<0.001)$ : the prevalence of abnormal QTc prolongation was $11 \%$ in males and $21 \%$ in females $(p<0.001)$. As QT intervals were different between the sexes, sex specific outcomes are presented.

A strong association was observed between crude QTc and age, $\mathrm{HbA}_{1 \mathrm{c}}$ and duration of diabetes (Table 1). There was no relation, however, between the QTc interval and duration of diabetes after adjusting for age and $\mathrm{HbA}_{1 \mathrm{c}}$, but the relation remained significant between QTc and age after adjusting for duration and $\mathrm{HbA}_{1 \mathrm{c}}$ and between QTc 
Table 1. Demographic details by the presence and absence of an abnormal QTc interval

\begin{tabular}{|c|c|c|c|c|}
\hline \multirow[t]{2}{*}{ Number (\%) } & \multicolumn{2}{|l|}{ Males } & \multicolumn{2}{|l|}{ Females } \\
\hline & $\begin{array}{l}\mathrm{QTc} \leq 0.44 \mathrm{~s} \\
1441(89)\end{array}$ & $\begin{array}{l}\text { QTe }>0.44 \mathrm{~s} \\
173(11)\end{array}$ & $\begin{array}{l}\text { QTc } \leq 0.44 \mathrm{~s} \\
1209(79)\end{array}$ & $\begin{array}{l}\text { QTc }>0.44 \mathrm{~s} \\
324(21)\end{array}$ \\
\hline $\begin{array}{l}\text { Age, years } \\
\text { Duration, years } \\
\mathrm{HbA}_{1 \mathrm{c}}, \%\end{array}$ & $\begin{array}{l}\text { Mean (SD) } \\
32.4(10.1) \\
14.4(9.2) \\
6.62(1.83)\end{array}$ & $\begin{array}{l}\text { Mean }(\text { SD) } \\
35.4(10.4)^{\mathrm{d}} \\
15.6(9.4) \\
7.06(1.84)^{\mathrm{c}}\end{array}$ & $\begin{array}{l}\text { Mean (SD) } \\
32.2(10.1) \\
14.9(9.2) \\
6.70(1.89)\end{array}$ & $\begin{array}{l}\text { Mean }(\text { SD) } \\
34.9(10.3)^{\mathrm{e}} \\
15.5(9.5) \\
7.03(1.92)^{\mathrm{c}}\end{array}$ \\
\hline $\begin{array}{l}\text { BMI, } \mathrm{kg} / \mathrm{m}^{2} \\
\text { Waist-to-Hip Ratio } \\
\text { Diastolic BP, } \mathrm{mm} \mathrm{Hg} \\
\text { Systolic BP, mm Hg } \\
\text { Insulin/Kg Body weight, U/kg } \\
\text { Insulin dose, U }\end{array}$ & $\begin{array}{l}\operatorname{Mean}^{\mathrm{a}}(\mathrm{SD}) \\
23.6(2.6) \\
0.88(0.08) \\
76.2(11.3) \\
123.5(16.7) \\
0.68(0.40) \\
49.0(28.0)\end{array}$ & $\begin{array}{l}\operatorname{Mean}^{\mathrm{a}}(\mathrm{SD}) \\
23.4(3.1) \\
0.89(0.08) \\
79.5(12.0)^{\mathrm{d}} \\
126.7(20.8)^{\mathrm{b}} \\
0.65(0.18) \\
45.6(13.4)\end{array}$ & $\begin{array}{l}\text { Mean }^{\mathrm{a}}(\mathrm{SD}) \\
23.4(3.05) \\
0.81(0.12) \\
73.5(11.0) \\
117.9(17.1) \\
0.69(0.30) \\
42.4(19.1)\end{array}$ & $\begin{array}{l}\operatorname{Mean}^{\mathrm{a}}(\text { SD) } \\
23.7(3.66) \\
0.80(0.11) \\
77.0(11.7)^{\mathrm{e}} \\
121.8(20.1)^{\mathrm{d}} \\
0.68(0.21) \\
42.4(13.8)\end{array}$ \\
\hline & $\%^{a}$ & $\%^{a}$ & $\%^{a}$ & $\%^{a}$ \\
\hline $\begin{array}{l}\text { Smoking Status } \\
\text { Ex- } \\
\text { Current }\end{array}$ & $\begin{array}{l}21.8 \\
34.2\end{array}$ & $\begin{array}{l}20.8 \\
41.3^{\mathrm{b}}\end{array}$ & $\begin{array}{l}12.7 \\
28.7\end{array}$ & $\begin{array}{l}17.4^{\mathrm{b}} \\
30.7\end{array}$ \\
\hline $\begin{array}{l}\text { Maximum Exercise } \\
\text { Mild, < once a week } \\
\text { Mild, weekly } \\
\text { Moderate, weekly } \\
\text { Vigorous, weekly }\end{array}$ & $\begin{array}{l}13.2 \\
86.1 \\
51.7 \\
41.9\end{array}$ & $\begin{array}{l}11.7 \\
88.3 \\
41.7 \\
41.4\end{array}$ & $\begin{array}{l}7.6 \\
92.4 \\
46.1 \\
21.1\end{array}$ & $\begin{array}{l}0.6^{\mathrm{d}} \\
99.4 \\
46.1 \\
21.5\end{array}$ \\
\hline
\end{tabular}

a Adjusted for age and $\mathrm{HbA}_{1 \mathrm{c}}$

Significant difference between QTc $\leq 0.44 \mathrm{~s}$ and QTc $>0.44$ s with: ${ }^{\mathrm{b}} p<0.05 ;{ }^{\mathrm{c}} p<0.01 ;{ }^{\mathrm{d}} p<0.001 ;{ }^{\mathrm{e}} p<0.0001$

Table 2. QTc interval by nephropathy, retinopathy and ischaemic heart disease

\begin{tabular}{|c|c|c|c|c|c|c|}
\hline & \multicolumn{3}{|l|}{ Males } & \multicolumn{3}{|l|}{ Females } \\
\hline & \multirow{2}{*}{$\begin{array}{l}\text { Mean QTc } \\
(95 \% \text { CI })\end{array}$} & \multicolumn{2}{|c|}{ QTe $>0.44 \mathrm{~s}$} & \multirow{2}{*}{$\begin{array}{l}\text { Mean QTc } \\
(95 \% \text { CI })\end{array}$} & \multicolumn{2}{|c|}{$\mathrm{QTc}>0.44 \mathrm{~s}$} \\
\hline & & Number & $\%^{\mathrm{a}}(95 \% \mathrm{CI})$ & & Number & $\%^{\mathrm{a}}(95 \% \mathrm{CI})$ \\
\hline \multicolumn{7}{|l|}{ Albumin excretion } \\
\hline$<20 \mu \mathrm{g} / \mathrm{min}$ & $0.410(0.408,0.411)$ & 90 & $9.5(7.4,11.5)$ & $0.421(0.420,0.423)$ & 200 & $18.9(16.3,21.5)$ \\
\hline $20-200 \mu \mathrm{g} / \mathrm{min}$ & $0.413(0.410,0.415)$ & 41 & $10.8(7.4,14.3)$ & $0.424(0.422,0.427)^{\mathrm{b}}$ & 73 & $25.6(19.4,31.8)$ \\
\hline $201+\mu \mathrm{g} / \mathrm{min}$ & $0.418(0.414,0.422)$ & 28 & $17.4(10.0,24.8)$ & $0.424(0.419,0.428)$ & 31 & $29.6(17.2,42.0)$ \\
\hline$P$-value testing for trend & 0.0003 & & $<0.02$ & 0.08 & & $<0.02$ \\
\hline \multicolumn{7}{|l|}{ Retinopathy } \\
\hline None & $0.408(0.406,0.410)$ & 42 & $6.8(4.6,8.9)$ & $0.421(0.419,0.422)$ & 111 & $17.2(13.8,20.6)$ \\
\hline Non-proliferative & $0.410(0.407,0.412)$ & 52 & $10.6(7.6,13.6)$ & $0.421(0.418,0.423)$ & 80 & $19.9(15.4,24.3)$ \\
\hline Proliferative & $0.412(0.408,0.417)$ & 11 & $7.6(1.7,13.4)$ & $0.422(0.419,0.426)$ & 31 & $18.3(11.4,25.3)$ \\
\hline$P$-value testing for trend & 0.14 & & 0.7 & 0.7 & & 0.3 \\
\hline \multicolumn{7}{|l|}{ Ischaemic heart disease } \\
\hline Absent & $0.411(0.409,0.412)$ & 150 & $10.3(8.6,11.9)$ & $0.422(0.421,0.423)$ & 282 & $19.8(17.5,22.1)$ \\
\hline Present & $0.423(0.418,0.428)$ & 23 & $18.9(10.3,27.6)$ & $0.429(0.425,0.433)$ & 41 & $31.4(20.2,42.5)$ \\
\hline $\begin{array}{l}P \text {-value testing for differences } \\
\text { between means }\end{array}$ & 0.0001 & & 0.002 & 0.002 & & $<0.001$ \\
\hline
\end{tabular}

${ }^{a}$ Adjusted for age and $\mathrm{HbA}_{1 \mathrm{c}}$

${ }^{\mathrm{b}}$ Significantly different from mean for albumin excretion $<20 \mu \mathrm{g} / \mathrm{min}$, with $p<0.05$

and $\mathrm{HbA}_{1 \mathrm{c}}$ after adjusting for age and duration. Therefore, all subsequent analyses were adjusted for these confounding factors (age and $\mathrm{HbA}_{1 \mathrm{c}}$ ). A significant relation was observed between QTc prolongation and both systolic and diastolic blood pressure in males and females. A higher prevalence of prolonged QTc was observed in male patients who were current smokers and female who were ex smokers (Table 1).

The relation between QTc and microvascular and macrovascular complications of diabetes was assessed (Table 2). In both, males and females, higher QTc intervals were observed in those with raised albumin excretion rates compared with those with nor- 
Table 3. Multivariate analysis examining the independent association of diabetic complications with QTc interval

\begin{tabular}{|c|c|c|c|c|c|c|}
\hline & \multicolumn{3}{|l|}{ Males } & \multicolumn{3}{|l|}{ Females } \\
\hline & $\begin{array}{l}\text { Standardised } \\
\text { regression } \\
\text { coefficient }\end{array}$ & SEM & $p$-value & $\begin{array}{l}\text { Standardised } \\
\text { regression } \\
\text { coefficient }\end{array}$ & SEM & $p$-value \\
\hline \multicolumn{7}{|l|}{ Model 1} \\
\hline Albumin excretion rate & 0.002 & 0.00066 & 0.001 & 0.0005 & 0.00064 & 0.3 \\
\hline Systolic blood pressure & 0.002 & 0.00068 & 0.002 & 0.003 & 0.0007 & 0.0001 \\
\hline Ex-smoking & 0.002 & 0.0017 & 0.2 & 0.003 & 0.0018 & 0.06 \\
\hline Current smoking & 0.003 & 0.0014 & 0.02 & 0.001 & 0.0014 & 0.4 \\
\hline \multicolumn{7}{|l|}{ Model 2} \\
\hline Ischaemic heart disease & 0.01 & 0.0025 & 0.0001 & 0.006 & 0.0022 & 0.008 \\
\hline Albumin excretion rate & 0.002 & 0.00067 & 0.005 & 0.0004 & 0.00064 & 0.6 \\
\hline Systolic blood pressure & 0.002 & 0.00068 & 0.003 & 0.003 & 0.00068 & 0.0001 \\
\hline Ex-smoking & 0.002 & 0.0017 & 0.2 & 0.003 & 0.0018 & 0.07 \\
\hline Current smoking & 0.003 & 0.0014 & 0.02 & 0.001 & 0.0014 & 0.4 \\
\hline \multicolumn{7}{|l|}{ Model 3} \\
\hline Peripheral neuropathy & 0.004 & 0.0016 & 0.009 & 0.0009 & 0.0015 & 0.5 \\
\hline Albumin excretion rate & 0.002 & 0.0007 & 0.01 & 0.0004 & 0.0007 & 0.6 \\
\hline Systolic blood pressure & 0.002 & 0.0007 & 0.0008 & 0.003 & 0.0007 & 0.0001 \\
\hline Ex-smoking & 0.002 & 0.0018 & 0.4 & 0.004 & 0.0018 & 0.04 \\
\hline Current smoking & 0.003 & 0.0015 & 0.07 & 0.0004 & 0.0014 & 0.8 \\
\hline
\end{tabular}

All models also included age and $\mathrm{HbA}_{1 \mathrm{c}}$

Table 4. QTc by peripheral and autonomic neuropathy

\begin{tabular}{|c|c|c|c|c|c|c|}
\hline & \multicolumn{3}{|l|}{ Males } & \multicolumn{3}{|l|}{ Females } \\
\hline & \multirow{2}{*}{$\begin{array}{l}\text { Mean QTc } \\
(95 \% \text { CI })\end{array}$} & \multicolumn{2}{|c|}{ QTc $>0.44 \mathrm{~s}$} & \multirow{2}{*}{$\begin{array}{l}\text { Mean QTc } \\
(95 \% \text { CI })\end{array}$} & \multicolumn{2}{|c|}{ QTc $>0.44 \mathrm{~s}$} \\
\hline & & Number & $\%^{\mathrm{a}}(95 \% \mathrm{CI})$ & & Number & $\%^{\mathrm{a}}(95 \% \mathrm{CI})$ \\
\hline Absent & $0.410(0.408,0.411)$ & 86 & $8.8(6.7,11.0)$ & $0.422(0.421,0.423)$ & 211 & $20.6(17.8,23.5)$ \\
\hline Present & $0.415(0.413,0.418)$ & 76 & $15.2(11.4,19.0)$ & $0.423(0.421,0.425)$ & 85 & $20.1(15.2,25.0)$ \\
\hline \multicolumn{7}{|l|}{$\begin{array}{l}\text { Heart rate variability } \\
\text { (R-R interval) }\end{array}$} \\
\hline$>1$ & $0.410(0.409,0.411)$ & 105 & $8.8(7.1,10.5)$ & $0.422(0.421,0.423)$ & 239 & $20.1(17.5,22.6)$ \\
\hline$\leq 1$ & $0.418(0.415,0.421)$ & 59 & $20.6(15.0,26.2)$ & $0.423(0.421,0.426)$ & 58 & $21.5(15.6,27.3)$ \\
\hline $\begin{array}{l}P \text {-value testing for group } \\
\text { differences }\end{array}$ & 0.0001 & & $<0.001$ & 0.3 & & 0.6 \\
\hline $\begin{array}{l}P \text {-value testing for group } \\
\text { differences }\end{array}$ & 0.8 & & 0.3 & 0.4 & & 0.2 \\
\hline
\end{tabular}

${ }^{a}$ Adjusted for age and $\mathrm{HbA}_{1 \mathrm{c}}$

mal rates and this relation was stronger in males than in females, even though for each level of complication status, females had a higher QTc than males. The regression coefficient $(\beta)$ for AER, in males, was $0.002(p=0.0003)$ and in females was 0.0009 $(p=0.08)$, however, the interaction between sex and AER was not significant. After adjusting for other variables as associated with abnormal QTe, i.e. blood pressure and smoking status (Table 1 ), the association between QTc and AER persisted in males ( $p=$ $0.001)$ but was somewhat attenuated for females $(p=0.3)$ (Table 3). Higher QTc intervals were also observed in those with evidence of IHD by medical history and resting ECG compared with those without IHD and, again, the association was stronger in males than females. For IHD, $\beta$ was $0.01(p=$ $0.0001)$ in males and was $0.006(p=0.002)$ in females $(p<0.05$ for the interaction between sex and IHD). Adjusting for AER and other variables associated with QTc, in the sex specific analysis, and also in the analysis examining the interaction between sex and IHD, the association between IHD and QTc persist- 
ed (Table 3). There was no association of QTc with retinopathy in either males or females.

The relation between QTc and neuropathy and heart rate variability were significant in males and these associations persisted even after adjustment for confounding factors, i.e. blood pressure and smoking (Table 4). Longer QTc intervals were observed in females with neuropathy and abnormal heart rate variability compared with those without, however these differences were not statistically significant.

\section{Discussion}

Several studies have described a poor survival prognosis for patients with Type I diabetes compared with non-diabetic populations. Sudden death has been reported as a common cause of death in insulin-dependent diabetic patients affected by autonomic neuropathy [21, 28-33]. Based on observations of the long QT syndrome [34, 35] and of sudden infant death [36, 37], it has been postulated that QT prolongation predisposes to cardiac arrhythmias and sudden death. The present study represents the largest study in which the QT interval has been measured in patients with Type I diabetes [2, 9-15] and offers the opportunity to examine exposure-complication relations in a large sample of European patients.

To reduce the bias introduced by errors in manual measurements, all the ECGs were recorded at the same paper speed and read by two observers as has been suggested $[38,39]$. The mean of the two readings has been used for analysis to reduce the bias of interobserver variability [12]. Although QTc does not vary much within people [40], 5 QT intervals and their corresponding RR intervals were measured, as a single cardiac cycle is possibly insufficient to represent a person's long term QTc interval length. Electrolytes, left ventricular hypertophy and drug information were not available in the EURODIAB study. This represents a limit in the interpretation of results: however, since this sample of patients is relatively young, the prevalence of left ventricular hypertrophy and percentage of patients with electrolytes disturbances or being prescribed relevant drugs or both should be very small and have little impact on the findings.

The QT interval duration was higher in females than in males and was independently associated with age and $\mathrm{HbA}_{1 \mathrm{c}}$. Moreover, an association was found with risk factors for mortality including blood pressure and smoking. The QTc was also correlated with IHD and nephropathy and this relation appeared to be stronger in males than in females. There was no relation between QT interval duration and retinopathy.

It has been shown that QTc interval is similar in boys and girls below age 15 years of age: thereafter, females tend to have longer QTc intervals than males [16]. Our findings confirm previous data reported in large studies of healthy groups [1], where the prevalence of QTc greater than $0.44 \mathrm{~s}$ was $5.02 \%$ in males and $15.9 \%$ in females. Unfortunately, the majority of studies of QT interval in diabetic patients are restricted to males or do not take sex into account. The difference between males and females is mentioned in many studies on QT intervals in non-diabetic subjects, but its physiological basis is still not clear.

Since QT interval has been shown to adapt in different ways to changes in heart rate in males and females [41], the use of a single heart rate correction formula could induce a sex-related error and a false sex difference in QTc length. On the other hand, some observations suggest an intrinsic sex-related difference in cardiac myocyte membrane action potentials. Females are at a higher risk of Torsade de Pointes during quinidine treatment and recently it has been shown that they have a greater increase in QTc interval for similar plasma drug concentrations compared with males [42]. Also female first-degree relatives of patients with congenital long QT syndrome have a higher risk of cardiac events [43]. Moreover, it has been shown in rabbits that outward myocyte potassium currents are slower in females than in males, accounting for longer QTc intervals in this model [36, 44].

Since cardiac ischaemia possibly prolongs the QTc interval by increasing the repolarization time [3] and prolonged QTc intervals have been described in post myocardial infarct patients [4-7, 45, 46], we evaluated the relation of QTc with IHD. Furthermore, prolonged QTc in IHD has been proposed as a risk factor for increased mortality [4-7], but this has been challenged $[3,45,46]$. In the EURODIAB study, the prevalence of IHD was $9 \%$ in males and $10 \%$ in females, whereas the prevalence of silent ischaemia (defined as ECG changes without prior positive history) was $6 \%$ [22]. The similar prevalence of IHD in males and females in the EURODIAB study would appear to rule out IHD as the cause of the higher prevalence of QTc prolongation in females compared with males. It is possible that IHD exerts a different effect on QTc prolongation in the sexes or QTc prolongation is associated with a different survival rate or both. This hypothesis cannot be evaluated in the present study because of its cross-sectional design but is supported by a recent study [47] in which QTc has been shown to be a significant independent predictor of mortality only in male postinfarction patients, with longer mean QTc and a lower mortality in female patients.

We found that mean adjusted QTc and the adjusted prevalence of QTc prolongation were associated with the presence of IHD in both sexes, although the relation was stronger in males. (The coefficient of contingency for males was 0.1 and for females 0.077). This relation suggests a possible role of IHD, even silent, in the pathogenesis of QTc pro- 
longation in Type I diabetic patients. In the EURODIAB study the prevalence of IHD was assessed by means of a resting ECG and it is known that an exercise ECG can reveal IHD more often in Type I diabetic patients [48]. Therefore, in a proportion of the patients with abnormal QTc and absence of IHD on resting ECGs $(10.3 \%$ of males and $19.8 \%$ of females) QTc prolongation could be attributed to undiagnosed cardiac ischaemia.

The association of age and blood pressure with QTc interval prolongation suggests that left ventricular hypertrophy could affect duration of QT. We cannot exclude this hypothesis as data on left ventricular hypertrophy were not available in the EURODIAB study but as those studies were relatively young, the prevalence of left ventricular hypertrophy would therefore be small and have little impact on the findings.

An association between QTc abnormalities and diabetic nephropathy is suggested by previous studies. Patients affected by Type I diabetes who develop proteinuria have a poor survival prognosis [49]. They show a high prevalence of IHD [50] and autonomic neuropathy $[51,52]$ which, in turn, are both associated with QTc prolongation [3,53] and a higher total and sudden mortality rate $[14,15,54]$. Recently a significant relation between QTc prolongation and mortality in Type I diabetic patients with overt proteinuria (>500 mg/24 h, no replacement therapy) was reported [8]. This suggests a role for QTc prolongation in the excess mortality of Type I diabetic patients with this complication, independently of autonomic neuropathy.

In our study, we describe for the first time an independent relation between QTc duration and AER in males and in females, with a higher prevalence of QTc prolongation even in patients with microalbuminuria compared with those with normoalbuminuria. This association was again slightly stronger in males than in females: the prevalence of prolonged QTc in females with normoalbuminuria was higher than in males with macroalbuminuria, with a trend similar to that observed for IHD.

The interest in exploring the relation of QTc with diabetic neuropathy derives from several observations. Experimental manipulations of the sympathetic nervous system have suggested that QTc duration is influenced by autonomic tone and QTc prolongation is regarded as the consequence of an imbalanced distribution of autonomic nervous system activity in the heart $[1,55,56]$. A role of autonomic neuropathy in the QTc prolongation in diabetic patients has been proposed after the observation that diabetic patients with it show longer QTc compared with those without this complication [2,9-13, 15]. A relation between QTc duration and results of cardiovascular tests for the assessment of autonomic function has been observed, leading to the proposal of QTc as a diagnostic tool for autonomic neuropathy $[12,53]$.
In our study male patients with neuropathy or impaired heart rate variability (an index of autonomic dysfunction) or both showed a higher mean adjusted QTc compared with male patients without this complication. A similar trend was observed for the prevalence of QTc prolongation suggesting a role for autonomic dysfunction in QTc prolongation in male patients. The relation between QTc prolongation and autonomic neuropathy was not observed among females. Note that female patients without neuropathy or impaired heart rate variability show an adjusted mean QTc and a prevalence of QTc prolongation similar to those of male patients with the complication. It is possible that some unidentified factors cause QTc prolongation in females to an extent that the presence of autonomic neuropathy is no more influential.

The EURODIAB IDDM Complication Study is a clinic-based and not a population-based study. The great majority of Type I diabetic patients in Europe, however, attend centres such as those taking part in the study. Nevertheless some degrees of selection bias could have occurred but, as we have argued previously [17], this should result in an underestimation of the risk factor/complication relation we are observing.

In conclusion, we have shown that QTc in Type I diabetic female patients is longer than in males, even in the absence of diabetic complications known to increase the risk of QTc prolongation.

Acknowledgements. We thank all the patients who took part in the study. The study was part of the EURODIAB Concerted Action Programme financially supported by the Commission of the European Union. Additional financial support was received from ICI UK, Fidia, Bayer, Miles-Ames, Novo Nordisk and Pfizer.

\section{EURODIAB Investigators}

B. Karamanos, C. Tountas, A. Kofinis, K. Petrou, N. Katsilambros, Hippokration Hospital, Athens, Greece.

R. Giorgino, M. Cignarelli, M. L. De Cicco, I. Ramunni, Istituto di Clinica Medica, endocrinologia et Malattie Metaboliche, Universita di Bari, Bari, Italy.

C. Ionescu-Tirgoviste, C. M. Iosif, D. Pitei, S. Buligescu, Clinic of Diabetes, Nutrition \& Metabolic Diseases, Bucharest, Romania.

G. Tamas, Z. Kerenyi, A. M. Ahmed, J. Toth, P. Kempler, Tetenyi Teaching Hospital and Semmelweis University, Budapest, Hungary.

S. Muntoni, M. Songini, M. Stabilini, M. Fossarello, S. Pintus, S. Muntoni, Centro Malattie Dismetaboliche and Ospedale San Michele, Cagliari, Italy.

J.B. Ferriss, C. C. Cronin, A.E. Whyte, P.E. Cleary, Cork Regional Hospital, Cork, Ireland.

M. Toeller, A. Klischan, T. Forst, F. A. Gries, Diabetes Forschungsinstitut, Universitat Dusseldorf, Germany.

R. Rottiers, H. Priem, University Hospital of Gent, Belgium. P. Ebeling, M. Sinisalo, V.A. Koivisto, University Hospital of Helsinki, Finland. 
B. Idzior-Walus, B. Solnica, L. Szopinska-Ciba, K. Solnica, University School of Medicine, Krakow, Poland.

H.M.J. Krans, H.H.P.J. Lemkes, J.J. Jansen, J. Brachter, University Hospital of Leiden, The Netherlands.

J. Nunes-Correa, J. Boavida, Portuguese Diabetic Association, Lisbon, Portugal.

G. Michel, R. Wirion, Centre Hospitalier, Luxembourg.

A. J. M. Boulton, H. Ashe, D. J. S. Fernando, Manchester Royal Infirmary, UK.

G.Pozza, G.Slaviero, G.Comi, B.Fattor, F.Bandello, Ospedale San Raffaele, Milan, Italy.

H. U.Janka, A. Nuber, H. Mehnert, City Hospital Schwabing, Munich, Germany.

D. Ben Soussan, M.-C.Fallas, P.Fallas, Centre Hospitalier de Valenciennes, France.

E.Jepson, S.McHardy-Young, Central Middlesex Hospital, and J.H.Fuller, D. J. Betteridge, M. Milne, University College Hospital, NW London.

G. Crepaldi, R. Nosadini, T.Segato, S.Piermarocchi, M. R.Cipollina, D.Fedele, P.Fioretto Instituto di Medicina Interna, Clinica Oculistica, Padua, Italy.

G. Cathelineau, B. Villatte Cathelineau, M. Jellal, N. Grodner, P. Gervais Feiss, Hospital Saint-Louis, Paris, France.

F. Santeusanio, G. Rosi, M.R.M. Ventura, C. Cagini, C. Marino, Instituto di Patologia Medica, Policlinico, Perugia, Italy.

R. Navalesi, G.Penno, R. Miccoli, M.Nannipieri, S. Manfredi, Instituto di Clinica Medica II, Pisa, Italy.

G. Ghirlanda, P.Cotroneo, A. Manto, C. Teodonio, A. Minnella, Universita Cattolica del Sacro Cuore, Rome, Italy.

J.D. Ward, S.Tesfaye, C.Mody, C.Rudd, Royal Hallamshire Hospital, Sheffield, UK.

G. M. Molinatti，F. Vitelli, M.Porta， G.F.Pagano, P.Cavallo Perin, M. Borra, R. Sivieri, Q. Carta, G.Petraroli, Clinica Medica B, Patologia Medica, Ospedale Molinette, and Ospedale "Agnelli", Turin, Italy.

N.Papazoglou， G. Manes， G. Triantaphyllou， A. Ioannides, G. Skazagar, I. Kontogiannis, General Hospital of Thessaloniki, Greece.

M. Muggeo, V.Cacciatori, F. Bellavere, P.Galante, M. L. Gemma, Cattedra di Malatties del Metabolismo, Verona, Italy.

K. Irsigler, H. Abrahamian, C. Gurdet, B.Hornlein, C. Willinger, Hospital Vienna Lainz, Austria.

S. Walford, E. V.Wardle, S. Hughes, New Cross Hospital, Wolverhampton, UK.

G. Roglic, Z. Resman, Z. Metelko, Z.Skrabalo, Vuk Vrhovac Institute for Diabetes, Zagreb, Croatia.

Steering Committee Members: J. H. Fuller (London), H. Keen, Chairman (London), H.M.J.Krans (Leiden), R. Navelesi (Pisa), A.-K.Sjolie (Aarhus), J.M.Stephenson (London), M. Toeller (Dusseldorf), G.-C. Viberti (London), J. Ward (Sheffield).

Co-ordinating Centre: J.H. Fuller, J.Stephenson, T.Partridge, M. Milne, U.C.L. Medical School, UK.

Central Laboratories: G.John, The Royal London Hospital, and G.-C.Viberti, M. Mattock, A.Collins, A.Dredge, R. Sharp, Guy's Hospital, London, UK.

Retinopathy Co-ordination: A.-K.Sjolie, Aarhus University Hospital, Denmark.

Retinopathy Grading Centre: E.Kohner, S. Aldington, S. Cockley, Hammersmith Hospital, London, UK.

\section{References}

1. Schouten EG, Dekker JM, Meppelimk P, Kolk FJ, Vanderbroucke JP, Pool J (1991) QT interval prolongation predicts cardiovascular mortality in an apparently healthy population. Circulation 84: 1516-1523

2. Sivieri R, Veglio M, Chinaglia A, Scaglione L, CavalloPerin P (1993) Prevalence of QT prolongation in a type 1 diabetic population and its association with autonomic neuropathy. Diabetic Medicine 10: 920-924

3. Surawicz B, Knoebel SB (1984) Long QT: good, bad or indifferent? J Am Coll Cardiol 4: 398-413

4. Moller M (1981) QT interval in relation to ventricular arrhythmias and sudden cardiac death in postmyocardial infarction patients. Acta Med Scand 210: 73-77

5. Ahnve S, Gilpin E, Madsen EB, Froehlicher V, Henning H, Ross J (1984) Prognostic importance of QTc interval at discharge after acute myocardial infarction: a multicenter study of 865 patients. Am Heart J 108: 395-400

6. Barber MJ, Mueller TM, Vavies BG, Gill RM, Zipes DP (1985) Interruption of sympathetic and vagal-mediated afferent response by transmural myocardial infarction. Circulation 72: 623-631

7. Schwartz PJ, Wolf S (1978) QT interval prolongation as a predictor of sudden death in patients with myocardial infarction. Circulation 57: 1074-1077

8. Sawicki PT, Dähne R, Bender R, Berger M (1996) Prolonged QT interval as a predictor of mortality in diabetic nephropathy. Diabetologia 39: 77-81

9. Jermendy G, Koltai MZ, Pogatsa G (1990) QT prolongation in type 2 (non-insulin-dependent) diabetic patients with cardiac autonomic neuropathy. Acta Diabetol 27: 295-301

10. Ewing DJ, Neilson JMM (1990) QT interval length and diabetic autonomic neuropathy. Diabet Med 7: 23-26

11. Chambers JB, Sampson MJ, Sprigings DC, Jackson G (1990) QT prolongation on the electrocardiogram in diabetic autonomic neuropathy. Diabet Med 7: 105-110

12. Gonin JM, Kadrofske MM, Schmaltz S, Bastyr EJ III, Vinik AI (1990) Corrected QT interval prolongation as diagnostic tool for assessment of cardiac autonomic neuropathy in diabetes mellitus. Diabetes Care 13: 68-71

13. Khan JK, Sisson JC, Vinik AI (1978) QT interval prolongation and sudden cardiac death in diabetic autonomic neuropathy. J Clin Endocrinol Metab 64: 751-754

14. Ewing DJ, Boland O, Neilson JMM, Cho CG, Clarke BF (1991) Autonomic neuropathy, QT interval lengthening and unexpected deaths in male patients. Diabetologia 34: 182-185

15. Bellavere F, Ferri M, Guarini L et al. (1988) Prolonged QT period in diabetic autonomic neuropathy: a possible role in sudden cardiac death? Br Heart J 59: 379-383

16. Rautaharjiu PM, Zhou SH, Wong S (1992) Sex differences in the evolution of the electrocardiographic QT interval with age. Can J Cardiol 8: 690-695

17. The Eurodiab IDDM Complications Study Group (1994) Microvascular and acute complications in insulin dependent diabetes mellitus: the EURODIAB IDDM Complication Study. Diabetologia 37: 278-285

18. Aldington SJ, Kohner EM, Meuer S, Sjolie A-K, The EURODIAB IDDM Complication Study Group (1995) Methodology for retinal photography and assessment of diabetic retinopathy: the EURODIAB IDDM Complication Study. Diabetologia 38: 437-444

19. Stephenson JM, Fuller JH, Viberti GC, Sjolie A-K, Navalesi $\mathrm{R}$ and the EURODIAB IDDM Complication Study Group (1995) Blood pressure, retinopathy and urinary albumin ex- 
cretion in insulin-dependent diabetes: The EURODIAB IDDM Complication Study. Diabetologia 38: 599-603

20. Tesfaye S, Stevens LK, Stephenson JM et al. and the EURODIAB IDDM Study Group (1996) Prevalence of diabetic peripheral neuropathy and its relation to glycaemic control and potential risk factors: the EURODIAB IDDM Complication Study. Diabetologia 39: 1377-1384

21. Ewing DJ, Martyn CN, Young RJ, Clarke BF (1985) The value of cardiovascular autonomic function tests: 10 years experience in diabetes. Diabetes Care 8: 491-498

22. Koivisto VA, Stevens LK, Mattock M et al. The EURODIAB IDDM Complications Study Group (1996) Cardiovascular disease and its risk factors in IDDM in Europe. Diabetes Care 19: 689-697

23. Ward DE (1998) Prolongation of the QT interval as an indicator of risk of a cardiac event. Eur Heart J 9 [Suppl 7]:139-144

24. Taran LM, Szilagyl N (1947) The duration of the electrical systole (QT) in acute rheumatic arthritis in children. Am Heart J 33: 14-26

25. Bazett HC (1920) An analysis of time-relations of electrocardiograms. Hearts 7: 353-370

26. Schwartz PJ, Wolf S (1978) QT interval prolongation as predictor of sudden death in patients with myocardial infarction. Circulation 57: 1074

27. Algra A, Tijssen J, Roelandt J, Pool J, Lubsen J (1991) QTc prolongation measured by standard 12 lead electrocardiogram is an independent risk factor for sudden death. Circulation 83: 1888-1894

28. Veglio M, Carpano-Maglioli P, Tonda L et al. (1990) Autonomic neuropathy in non-insulin-dependent diabetic patients: correlation with age, sex, duration and metabolic control of diabetes. Diabetes Metab 16: 200-206

29. O'Brien IAD, O'Hare JP, Lewin G, Corral RJM (1986) The prevalence of autonomic neuropathy in insulin-dependent diabetes mellitus: a controlled study based on heart rate variability. QJM 234: 957-967

30. Ewing DJ, Campbell IW, Clarke BF (1980) The natural history of diabetic autonomic neuropathy. QJM 95: 193-196

31. Watkins PJ (1990) Diabetic autonomic neuropathy. New Engl J Med 322: 1078-1079

32. Page MM, Watkins PJ (1978) Cardiorespiratory arrest and diabetic autonomic neuropathy. Lancet 1: 14-16

33. Lloyd-Mostyn RH, Watkins PJ (1975) Defective innervation of heart in diabetic autonomic neuropathy. BMJ 3: 15-18

34. Schwartz PJ (1984) Sympathetic imbalance and cardiac arrhythmias. In: Randall WC (ed) Nervous control of cardiovascular function. Oxford University Press, New York, pp 225-252

35. Schwartz PJ (1982) Idiopathic long QT syndrome: progress and questions. Am Heart J 109: 399-411

36. Schwartz PJ, Montemerlo M, Facchini M et al. (1982) The QT interval throughout the first six months of life: a prospective study. Circulation 66: 496-501.

37. Schwartz PJ (1987) The quest for the mechanism of the sudden infant death syndrome: doubts and progress. Circulation 75: 667-683

38. Ahnve S (1985) Errors in visual determination of corrected QT (QTc) interval during acute myocardial infarction. J Am Coll Cardiol 5: 699-702

39. Murray A, McLaughlin NB, Bourke PJ, Colin Doig J, Furnis SS, Campbell RWF (1994) Errors in manual measurement of QT intervals. BMJ 71: 386-390
40. Ahnve S (1985) QT interval prolongation in acute myocardial infarction. Eur Heart J 6 [Suppl]:85-95

41. Lax KG, Moss AJ (1996) Gender-specific dynamics of the QT-heart rate relationship during upright treadmill exercise. Circulation 94 [Suppl 1]:451

42. Benton RE, Sale M, Chen Y, Trapnel CB, Flochkart DA, Woosley RL (1996) Women have greater QTc prolongation with quinidine than men. Circulation 94 [Suppl 1]:737

43. Zareba W, Moss AJ, Le Cessie S et al. (1995) Risk of cardiac events in family members of patients with long QT syndrome. J Am Coll Cardiol 26: 1685-1691

44. Drici MD, Ducic I, Morad M, Woosley RL (1996) Gender difference in cardiac repolarisation depends on $\mathrm{Ik} 1$ and Ito $\mathrm{K}+$ channel currents in the rabbits. Circulation 94[Suppl 1]:473

45. Wheelan K, Mukharji J, Rude PE (1986) Sudden death and its relation to QT interval prolongation after acute myocardial infarction: two-year follow up. Am J Cardiol 57: 745-750

46. Phjola-Sintonen S, Siltanen P, Haapokoski J (1986) Usefulness of QTc interval in the discharge electrocardiogram for predicting survival after acute myocardial infarction. Am J Cardiol 57: 1066-1068

47. Zareba W, Moss AJ (1996) Gender related differences in prognostic significance of QTc and QRS duration in postinfarction patients. Circulation 94 [Suppl 1]:450

48. Karlefors T (1966) Circulatory studies during exercise with particular reference to diabetics. Acta Med Scand 180[Suppl 449]:1-87

49. Borch-Johnsen K, Kreiner S, Deckert T (1986) Mortality of type I (insulin-dependent) diabetes mellitus in Denmark: a study of relative mortality in 2930 Danish type 1 diabetic patients diagnosed from 1933 to 1972. Diabetologia 29: 767-772

50. Jensen T, Borch-JohnsenK, Koefoed-Enevoldsen A, Deckert T (1987) Coronary heart disease in young type 1 (insulin-dependent) diabetic patients with and without diabetic nephropathy: incidence and risk factors. Diabetologia 30: 144-148

51. Mølgaard H, Christensen PD, Hermansen K, Sørensen KE, Christensen CK, Mogensen CE (1994) Early recognition of autonomic dysfunction in microalbuminuria: significance for cardiovascular mortality in diabetes mellitus? Diabetologia 37: 788-796

52. Mølgard H, Christensen PD, Sørensen KE, Christensen CK, Mogensen CE (1992) Association of 24-h cardiac parasympathetic activity and degree of nephropathy in IDDM. Diabetes 41: 812-817

53. Veglio M, Chinaglia A, Borra M, Cavallo-Perin P (1995) Does abnormal QT interval prolongation reflect autonomic dysfunction in diabetic patients? QTc interval measure versus standardised tests in diabetic autonomic neuropathy. Diabet Med 12: 302-306

54. Diabetes Epidemiology Research International Mortality Study Group (1991) International evaluation of cause specific mortality in IDDM. Diabetes Care 14: 55-60

55. Yanowitz F, Preston JB, Abildskov JA (1966) Functional distribution of right and left stellate innervation to the ventricles. Circ Res 18: 416-428

56. Kahima T, Tamaka H, Minagoe S, Toda H (1981) Electrocardiographic changes induced by the stellate ganglion block in normal subjects. J Electrocardiol 14: 169-174 